\title{
Current Perspectives on Social Mapping of Urban Territories
}

\author{
Marat Rashitovich Safiullin ${ }^{1,2}$, Polina Olegovna Ermolaeva ${ }^{1,2}$, Oleg Petrovich Yermolaev ${ }^{2} \&$ Renat Nailevich $^{2}$ \\ Selivanov $^{2}$ \\ ${ }^{1}$ Kazan (Volga region) Federal University, Center of Advanced Economic Research in the Academy of Sciences \\ of the Republic of Tatarstan, Kazan, Russian Federation \\ ${ }^{2}$ Kazan (Volga region) Federal University Kazan, Russian Federation \\ Correspondence: Marat Rashitovich Safiullin, Kazan (Volga region) Federal University, Center of Advanced \\ Economic Research in the Academy of Sciences of the Republic of Tatarstan, Kazan, Kremlevskaya, 18, 420008, \\ Kazan, Ostrovskogo 23, 420111, Russian Federation. E-mail: c.p@tatar.ru
}

\author{
Received: October 8, 2014 Accepted: October 20, 2014 Online Published: February 25, 2015 \\ doi:10.5539/ass.v11n6p207 URL: http://dx.doi.org/10.5539/ass.v11n6p207
}

\begin{abstract}
The article provides insights on the conceptualization of social mapping and its three main types: statistical, anthropological and network-oriented. Each perspective is described in detail and illustrated by examples. Artificial Neuron Networks with a particular interest to self-organizing maps are embedded in the analysis as a cutting-edge technique of social mapping now actively used by interdisciplinary researchers. The authors argue that despite the variety of social mapping techniques, they all have common features such as ordering and grouping of objects based on particular framework and empirical data, flexibility, visibility, citizens' engagement on developing maps. Along with advantages, authors acknowledge such limitations of social mapping as data exclusion, data scale incompatibility and complexity of datasets that are beyond the cognitive abilities of the analyst.
\end{abstract}

Keywords: GIS, QGIS, PPGIS, artificial neuron networks, self-organizing maps, social mapping, urban territory

\section{Introduction}

Social mapping is nowadays actively used in examining social and environmental issues of urban territories and communities. A map acts as an instrument of communication to locals, administrations, developers, and city's stakeholders.

Social mapping is nowadays highly trendy technologies under different social spheres including academic, public sphere (for example, in social work, city planning, education etc.). The popularity of the method across disciplines is connected with the development of information technologies, the popularity of mental mapping techniques, QGIS, PPGIS and an analysis of the distribution of the social problems in the city. Issues have included the employment of social mapping to better capture community values and react to neighborhood renewal programs; GIS as a participatory research instrument; mapping fear and misunderstandings of urban space, environmental and social well-being and mapping etc.

The literature suggests several ways of interpretation of social mapping. First tradition is employed primarily in cartography, geology, geography. According to it, social mapping is method of modeling a graphic and digital image of GIS and geospatial data with the identification of its coordinate and attributive data. Second approach talks about social mapping as a method of modeling, visualization and graphic representation of any spatial localized information according for the purpose to gain knowledge of the represented phenomena. Third, most widely used, tradition incorporates the understanding of social mapping as a method of graphic and semantic description of any material and abstract object which allows consistently describing, group and generalizing of data. It is a method of fixing various features of the territory (social problems, groups' interaction, social well-being, etc.) by means of social maps. Social mapping comprise the complex multiple-factor analysis of any social phenomenon (for example, the level of security on a particular territory, unemployment rate, awareness of environmental problems) that in turn causes creation of multilayered interactive maps.

\section{Types of Social Mapping}

There are several approaches aiming at studying various aspects of social mapping: statistical, anthropological 
and network-oriented.

The statistical approach is important for authorities in the social sphere, because this approach seeks to represent quantitative data from official statistics and sociological research. The given approach is mostly used for the purposes of analysis of the spatial and social distribution of social issues (crime, social differentiation, unemployment, etc.). It includes the analysis of not only a social context (demographic, cultural, historical, religious), but also wider geographical, social and economic and legal fabrics. It is widely used in the social geography and sociology. For example, in Figure 1 there is a distribution of clusters of the type of the real estate of the city of Kazan based on citizens' perception of the environmental condition of the area and the local authorities activities' towards environmental advancement. Analyzing spatial distribution of citizens' opinion it is possible to draw a conclusion regarding citizens' environmental concerns over environmental problems in general and identify the exact geographic location of critical zones or territories with valuable natural features. It is worth emphasizing that a great number of urban landscape units impose its own specific restrictions. In the given map the analysis of spatial distribution of indexes could provide further recommendations for selection of the most beneficial residential territories of the city with respect to environmental conditions and optimal expenses on residential real estate property units.

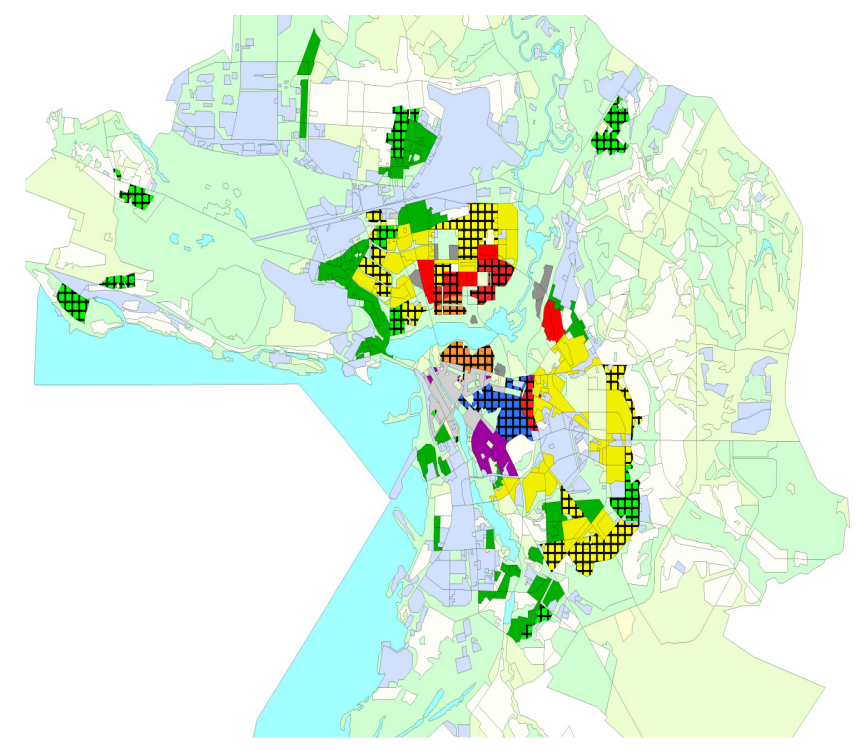

Figure 1. Map of the environmental and ecological classification of the real estate of the city of Kazan, Russia

Anthropological approach in social mapping is based on the understanding that any social phenomenon is centered around people's perception of the territory. This approach contains is based on the tradition of the ethnographic researches, visual anthropology, semiotics and cultural studies. In Western literature this approach is usually associated with QGIS. QGIS aims at incorporating into GIS more qualitative data than has previously been intergrated. QGIS can also be located among those "post-positivist, poststructuralist, and non-representational approaches in contemporary cultural geography that strive to reconcile social-cultural and spatial-analytical geographies". The qualitative aspect can be related to the qualitative nature of either the data gathered (e.g., photographs, sketches, mental maps, social behavior maps, audio and video records, etc.) or the data analysis techniques (e.g., discourse analysis, triangulation, and grounded theory). For example, Figure 2 presents sketch map with coded symbology of residence, employment, and commuting experiences.

Often, this method is embedded in community-based and participatory planning projects where hidden meaning of context and the represented groups is crucial. QGIS can advance geography and social sciences from an top to down approachh and objective science to a more subjective that helps a researcher to capture deeper understanding of the actors' daily life practices and their meanings via ethnography. In the given perspective, study becomes genuinely a flexible emergent process and "partial and situated". For example, McLafferty articulates a story of how women worried about breast cancer employed GIS to analyze the relationship between environmental threats and the geographical dissemination of disease in suburban Long Island, New York. Authors argue that GIS is "more than a computer-based technology" and can not only operate as "a vehicle for women's empowerment" but also empower other, especially vulnerable groups. 
Table 1.

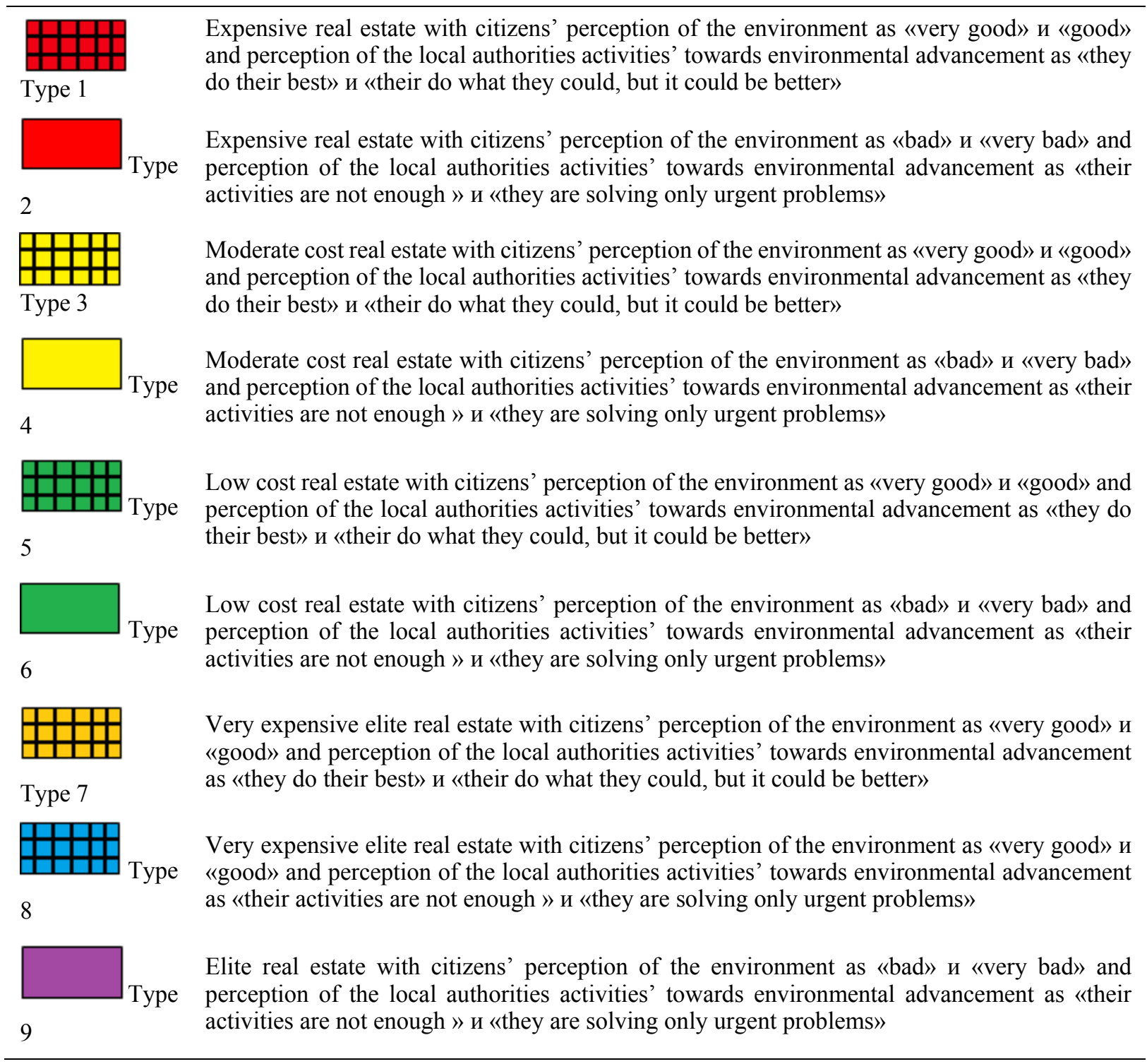

Finally, network-oriented approach displays various forms of social interaction among groups. The social map is presented in the form of the networks: the relations and communications of individuals and groups. Under this approach many research objectives could be solved: distinctions of feedback between individuals, groups, between people and the territory; comparison of persons, groups and relations; comparison between territories and regions. For example, Figure 3 presents a network map in Twitter of the conference members after and before the event. 


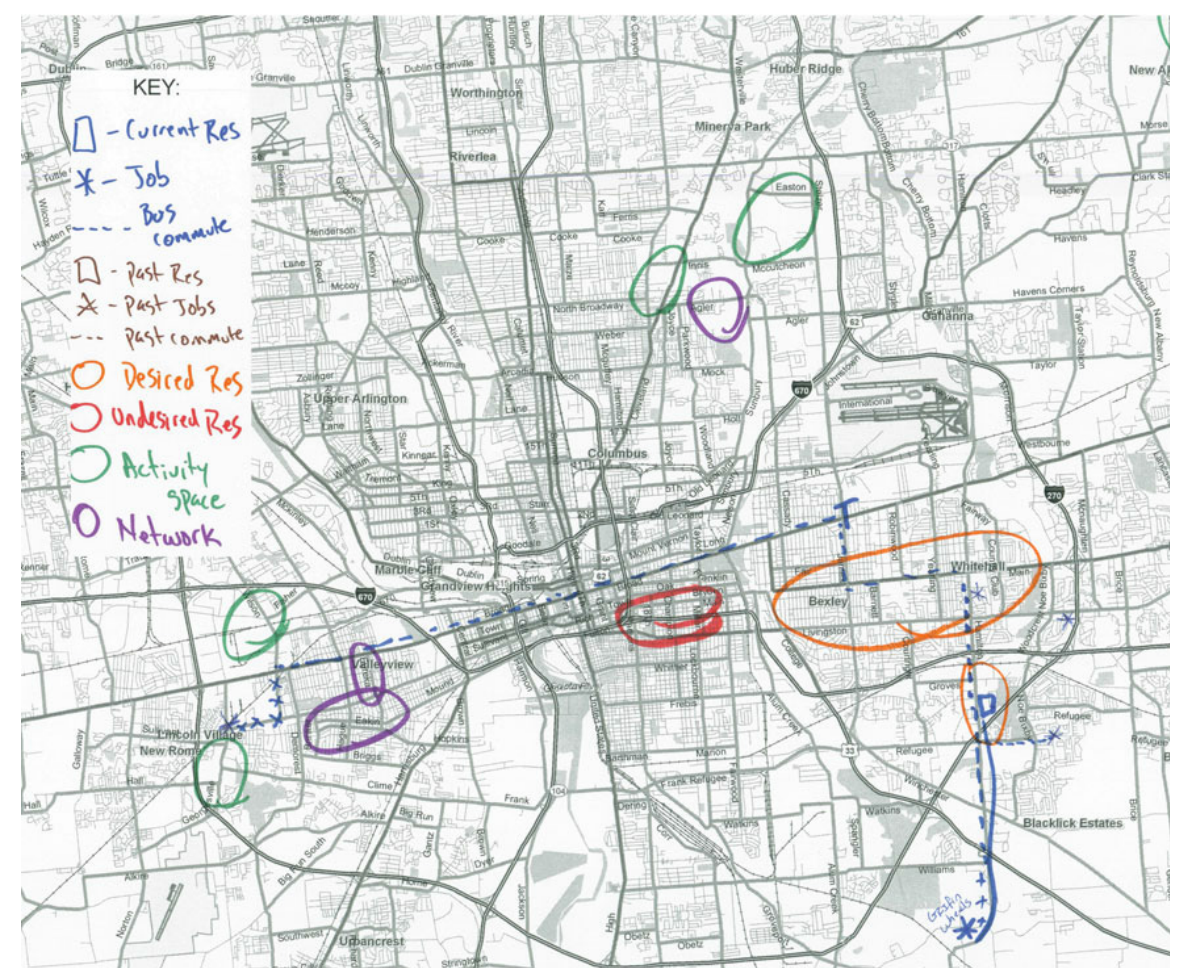

Figure 2. Original sketch map example from one interview subject ("Hank") in Columbus, Ohio, with coded symbology of residence, employment, and commuting experiences

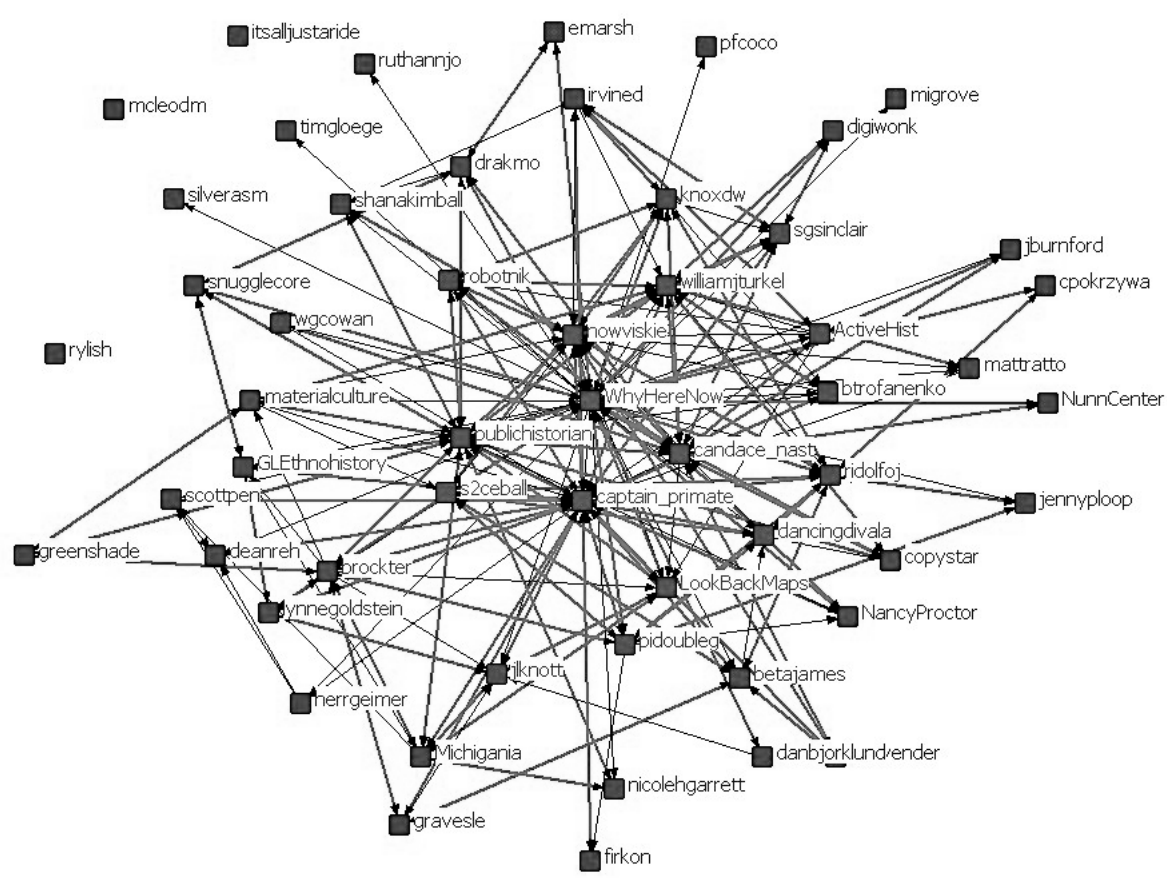

Figure 3. Network map of conference members in Twitter

\section{Employment of Artificial Neuron Networks in Social Mapping}

The last few years have witnessed a rapid increase of interest to Artificial Neuron Networks (ANN) technologies. Such a burst of interest was initiated by both theoretical and application-specific endeavors. They are motivated by ideas from neuroscience, where a complicated "computing" system can be developed from a network of humble processing units. New opportunities opened up for ANN application in the spheres earlier associated 
only with a human intellect, such as development of intelligent machines endowed with a human-level ability to learn and remember.

Non-parametric methods based on Kohonen's neural networks allow for the approximation of non-stop alteration of the object's features. So far as the topological relations are predetermined by the position on the ordination plane, the process of formation of the reflection of data is determined as an algorithm of "self-organizing" maps (SOM).

SOM is a type of Neural Network which allows to solve non-linear problems with highly-dimensional data by organizing them into groups on the base of their similarity. Traditionally SOM is considered to be an empirical algorithm. Conclusions about the structure of data are made on the basis of visual analysis of the received map. The main advantage of the SOM model is its ability of generalization. The SOM method is employed to different data types that can be presented by vectors.

Nowadays the SOM is exercised for the visualization of nonlinear relations of multidimensional data and dimensionality reduction. The examples of recent research which applies SOM involves Arribas-Bel Daniel and Lidia Diappi and Paola Bolchi. Deboeck applied a SOM for exploring global financial data, Paez, Scott, Potoglou, Kanaroglou, and Newbold embedded a SOM to investigate the spatial and demographic variability in elderly travel behaviours in the Hamilton, Ontario, area, Gorricha and Lobo employed color coding to combine the SOM output with cartographic representation of the underlying geospatial input data. Ju, Lam, and Chen utilize SOM to analyze ten socio-economic variables by Census block groups of New Orleans. Andrienko et al. (2010) demonstrated applying the SOM method to identify patterns in a 41-year time series of seven crime rate features across different states of USA. According to the result, Andrienko and colleagues examined spatiotemporal patterns of crime rates throughout the USA. Delmelle, Thill, Furuseth, and Ludden examined neighbourhood 17 quality of life indicators in the city of Charlotte, North Carolina between 2000 and 2010 by connecting SOM output nodes the output nodes for the same neighbourhood across time. Some authors attempted to apply SOM for purposes of landscape zoning in the territory of the Republic of Tatarstan, Russia.

Mathematical analysis of SOM is a difficult by virtue of the heuristic base of the algorithm. Thus, so far Kohonen's neural networks and their generalizations remain to be almost the only tool (due to adaptability and self-organization of a neural network which does not require any preparatory calibration of data and is resistant to noises and distortions) to obtain ordination and identify the structure of objects with regard to the entirety of data.

\section{Discussion}

Despite the variety of social mapping techniques, they all have common features such as ordering and grouping of objects based on particular framework and empirical data. All the given techniques are characterized by its flexibility, visibility, "model" representation of the processes of a territory; availability and accessibility to the end user; citizens' engagement on developing maps. They are techniques aiming at accomplishing of various data gathering including individual and social experiences and practices, visualizing socio-spatial processes, eliminating barriers of positionality in study, and creating new implications of GIS. Along with pronounced advantages, it has such limitations as data exclusion and data scale incompatibility. The possible data elimination in changing deep, complex ethnographic data to GIS summaries, codes, and symbols scale incompatibility among multiple layers of data in GIS can be deceptive with a certain intersection of quantitative data gathered in official urban units (e.g., districts or neighborhoods) with ethnographic data collected at the personal level. Moreover, mapping can be difficult though, when the size and complexity of datasets are beyond the cognitive abilities of the analyst.

\section{Summary}

Modern social mapping goes far beyond the boundaries of traditional construction of socio-economic maps, GIS and disseminates beyond research and academic areas. Of all types of mapping it has experienced perhaps, the most radical change in all of its objectives. The term 'social mapping' is increasingly being used in different contexts sometimes outside the spatial or graphical display of social landscapes. Social mapping has become an effective tool for identification of spatial relationships with the placement of sites and territories which citizens often visit and live in, regions of social tension. It can play an important role for a city's various stakeholders for social monitoring and improvement of a particular urban space.

\section{Acknowledgements}

The research was supported financially by the grant of the President of the Russian Federation as part of the project "Development of the social and environmental map of the territory of a big city with the employment of 
the modern GIS and connectionist technologies (interdisciplinary approach)”, project № MK-3033.2014.6. The publication of article was supported of the grant assigned to the Kazan Federal University for fulfillment of the government order in the sphere of scientific activity and by the subsidy of the Russian Government to support the Program of Competitive Growth of Kazan Federal University among World's Leading Academic Centres.

\section{References}

Andrienko et al. (2010). Space-in-time and time-in-space Self-Organizing Maps for exploring spatiotemporal patterns. In G. Melançon, T. Munzner, \& D. Weiskopf (Eds.), EuroVis'10 Proceedings of the 12th Eurographics/IEEE-VGTC Conference on Visualization (pp. 913-922). Aire-la-Ville, Switzerland: Eurographics Association.

Arribas-Bel, D., Kourtit, K., \& Nijkamp, P. (2012). Benchmarking of world cities through Self-Organizing Maps. Cities.

Bagheri, N. (2014). What qualitative GIS maps tell and don't tell: Insights from mapping women in Tehran's public spaces. Journal of Cultural Geography, 31(2), 166-178. http://dx.doi.org/10.1080/08873631.2014.906848

Boschmann, E. E., \& Cubbon, E. (2014). Sketch Maps and Qualitative GIS: Using Cartographies of Individual Spatial Narratives in Geographic Research. The Professional Geographer, 66(2), 236-248. http://dx.doi.org/ $10.1080 / 00330124.2013 .781490$

Deboeck, G. (1998). Best practice in data mining using Self-Organizing Maps. In G. Deboeck (Ed.), Visual explorations in finance with Self-Organizing Maps (pp. 203-229). London: Springer. http://dx.doi.org/10. 1007/978-1-4471-3913-3_15

Delmelle, E., Thill, J. C., Furuseth, O., \& Ludden, T. (2013). Trajectories of multidimensional neighbourhood quality of life change. Urban Studies, 50(5), 923-941. http://dx.doi.org/10.1177/0042098012458003

Diappi, L., Bolchi, P., \& Gaeta, L. (2012). Gentrification Without Exclusion? A SOM Neural network Investigation on the Isola District in Milan. In L. Diappi (Ed.), Emergent Phenomena in Housing Markets. Gentrification, Housing search, Polarization. Berlin: Springer heidelberg.

Elwood, S., \& Leitner, H. (1998). GIS and community based planning: Exploring the diversity of neighbourhood perspectives and needs. Cartography and Geographic Information Science, 25, 77-88. http://dx.doi.org/ $10.1559 / 152304098782594553$

Ermolaeva, P. O. (n. d.). Citizen (dis)engagement during assessment of sports mega-events: The case of the 2013 Universiade in Kazan, Russia' in Impact Assessment and Project Appraisal. Taylor \& Francis, 2014. On-line. Retrieved from http://www.tandfonline.com/eprint/BsRCSNseAAvSA2ESKrSX/full\#.UuaBTdeoXIU

Ermolaeva, P. O., Safiullin, M. R., Elshin, L. A., Shakirova, A. I., \& Prygonova, M. I. (2013). Influence of Territorial Ecological Load Factors on Social and Economic Well-Being of Population: Methodology Development and Econometric Model Construction. World Applied Sciences Journal, 25(7), 1057-1061.

Evteev, O. A. (1999). Designing and development of social and economic maps. M: MSU.

Gorricha, J., \& Lobo, V. (2012). Improvements on the visualization of clusters in georeferenced data using Self-Organizing Maps. Computers \& Geosciences, 43, 177-186. http://dx.doi.org/10.1016/j.cageo.2011. 10.008

GOST P 52438-2005 Geographical informational systems. Terms and definitions. (2006). M:Standartform.

Haraway, D. (1991). Simians, cyborgs, and women: The reinvention of nature. New York, NY: Routledge.

Ju, W., Lam, N. S. N., \& Chen, J. (2006). Application of Kohonen Self-Organizing Map for urban structure analysis. In Proceedings of IEEE International Conference on Granular Computing, Atlanta, Georgia, USA.

Jung, J. K., \& Elwood, S. (2010). Extending the qualitative capabilities of GIS: Computer-aided qualitative GIS. Transactions in GIS, 14(1), 63-87. http://dx.doi.org/10.1111/j.1467-9671.2009.01182.x

Kohonen, T. N. (1984). Self-organization and associative memory. Series in Information Sciences (No. 7, pp. 241-298). T. N. Kohonen. Z. Ges. Erdkunde Berlin.

Kohonen, T. N. (2001). Self-organizing maps. Berlin, Springer. http://dx.doi.org/10.1007/978-3-642-56927-2

Koua, E. L. (2003). Using Self-Organizing Maps for information visualization and knowledge discovery in complex geospatial datasets. In 21st International Cartographic Conference (pp. 1694-1702).

Kwan, M. P. (2004). Beyond difference: From canonical geography to hybrid geographies. Annals of the Association of American Geographers, 94(4), 756-763. 
Lee, A. C. D., \& Rinner, C. (2014). Visualizing urban social change with Self-Organizing Maps: Toronto neighbourhoods. 1996-2006, Habitat International.

Matei, S., Ball-Rokeach, S., \& Qiu, J. (2001). Fear and misperception of Los Angeles urban space: A spatial-statistical study of communication-shaped mental maps. Communication Research, 28, 429-463. http://dx.doi.org/10.1177/009365001028004004

McLafferty, S. L. (2002). Mapping women's worlds: Knowledge, power and the bounds of GIS. Gender, Place and Culture, 9(3), 263-269. http://dx.doi.org/10.1080/0966369022000003879

McLafferty, S. L. (2005). Women and GIS: Geospatial technologies and feminist geographies. Cartographica, 40(4), 37-45. http://dx.doi.org/10.3138/1341-21JT-4P83-1651

Paez, A., Scott, D., Potoglou, D., Kanaroglou, P., \& Newbold, K. B. (2007). Elderly mobility: Demographic and spatial analysis of trip making in the Hamilton CMA, Canada. Urban Studies, 44(1), 123-146. http://dx.doi. org $/ 10.1080 / 00420980601023885$

Puzchnko, Y. G. (2004). Mathematical Methods in Ecological and Geographical Studies (p. 95). Academia. Moscow.

Safiullin, M. R., Elshin, L. A., \& Shakirova, A. I. (2012). Assessment of the Business and Economic Activity as a Tool of Short-Term Forecasting. Vestnik Rossiyskoy Akademii Nauk, 7, 623.

Safiullin, M. R., Elshin, L. A., Shakirova, A. I., Ermolaeva, P. O., \& Prygunova, M. I. (2013). Influence of Territorial Ecological Load Factors on Social-and-Economic Well-Being of Population: Methodology Development and Econometric Model Construction. World Applied Sciences Journal, 25(7), 1057-1061.

Saveliyev, A. A. (2004). Modeling of spatial pattern of vegetation mantle: Geo-information approach (p. 244). Kazan, Kazan State University Publishing House.

Saveliyev, A. A., Yermolayev, O. P., Mukharamova, S. S., \& Maltsev, K. A. (2005). Approaches to relief zoning on the basis of morphometric parameters with the use of artificial neural networks. In Proceedings of the XII Congress of the Russian Geographic Society. Geoecology and Management of natural resources, 4, 348-356.

Semenova, V. (2009). Mapping of an urban space: Key approaches for the visual analysis. Visual antropology: City maps of memory. M: Varyant.

Silva, B., \& Marques, N. (2010). Feature clustering with self-organizing maps and an application to financial time-series for portfolio selection. International Conference of neural Computation.

Skalaban, I. A. (2012). Social mapping as a method of analysis of the social and territorial space. Journal of Social Policy, 10(1).

Takatsuka, M. (2001). An application of the Self-Organizing Map and interactive 3-D visualization to geospatial data. In 6th International Conference on Geo-Computation (pp. 1-9). Brisbane: GeoComputaion Conference Proceedings.

Trochim, W., \& Kane, M. (2005). Concept mapping: An introduction to structured conceptualization in health care. International Journal for Quality in Health Care, 17(3), 187-191. http://dx.doi.org/10.1093/intqhe/mzi038

Vajjhala, S. (2005). Integrating GIS and participatory mapping in community development planning. Presented at 25th Annual ESRI User Conference, San Diego, CA, July 25-29. Retrieved February 14, 2007, from http://proceedings.esri.com/library/userconf/proc05/abstracts/a1622.html

Yermolaev, O. P., \& Selivanov, R. N. (2014). The Use of Automated Geomorphological Clustering for Purposes of Urban Planning (The Example of the City of Kazan). World Applied Sciences Journal, 30(11), 1648-1655.

Yermolaev, O. P. (2004). Erosion in basin geosystems of the Middle Volga (from a landscape analysis perspective) (pp. 60-66). Sediment Transfer through the Fluvial System (Proceedings of a symposium held (Moscow, August 2004). London.

\section{Copyrights}

Copyright for this article is retained by the author(s), with first publication rights granted to the journal.

This is an open-access article distributed under the terms and conditions of the Creative Commons Attribution license (http://creativecommons.org/licenses/by/3.0/). 